\title{
AVALIAÇÃO DAS CONDIÇÕES SÓCIO-ECONÔMICO- AMBIENTAIS DE ALGUMAS PROPRIEDADES AGRÍCOLAS NO MUNICÍPIO DE SANTA RITA DO PASSA QUATRO - SP
}

\author{
Sérgio Luís de Carvalho ${ }^{1}$
}

Flávia de Almeida ${ }^{2}$

\author{
Elizete A. C. Freitas Lima ${ }^{3}$
}

RESUMO: Este trabalho teve como objetivo avaliar possíveis problemas ambientais existentes em propriedades agrícolas do município de Santa Rita do Passa Quatro e como esses problemas são tratados pelos proprietários. Para isto foi elaborado um questionário com 16 questões abertas e de múltipla escolha tratando das questões sócio-econômicas, bem como, os principais problemas ambientais existentes nestas propriedades. O questionário foi respondido junto aos agricultores e pecuaristas responsáveis, num total de 30 propriedades que variaram de pequena, a média e grande extensão. A atividade agropecuária foi relatada em $30 \%$ das propriedades. Equipamentos completos de proteção para a aplicação de defensivos agrícolas são utilizados por $60 \%$ dos proprietários, sendo que a maioria usa apenas máscaras. As embalagens de agrotóxicos são enterradas em $80 \%$ das propriedades e sua reutilização ocorre em $14 \%$ dos casos. O esgoto é lançado em fossas em $88 \%$ das propriedades e o lixo doméstico é queimado em $52 \%$ delas. As matas ciliares foram relatadas como conservadas em $70 \%$ das propriedades. $O$ estudo ainda detectou que $24 \%$ das propriedades apresentavam problemas de erosão do solo, apesar de não terem sido registrados problemas com o assoreamento dos córregos e rios presentes nas propriedades, possivelmente em decorrência da presença das matas ciliares. Pretende-se com as informações obtidas com o presente

\footnotetext{
${ }^{1},{ }^{3}$ Docentes do Departamento de Biologia e Zootecnia da Faculdade de Engenharia de Ilha Solteira (UNESP). E-mails: sergicar@bio.feis.unesp.br; eacfl@bio.feis.unesp.br.

${ }^{2}$ Eng. Agrônoma, Faculdade de Engenharia de Ilha Solteira (UNESP)
} 
trabalho fornecer subsídios que possibilitem implementar futuros programas de educação ambiental, visando uma maior conscientização e conservação do meio ambiente.

\section{INTRODUÇÃO}

Segundo Amorim (1997), qualquer atividade econômica causa alguma modificação no meio ambiente. Estudar e tentar entender estas mudanças são um bom começo para que se possa evitá-las ou minimizar os seus efeitos.

As ações antrópicas sobre ambientes naturais vêm provocando grandes alterações nos ecossistemas, sem considerar uma sustentabilidade a curto, médio e longo prazo. $\mathrm{O}$ resultado disto é uma crescente degradação ambiental, piorando a qualidade de vida e o bem-estar das populações, sendo que a cada ano são explorados os recursos naturais, desordenadamente, comprometendo a capacidade das futuras gerações de satisfazer as suas necessidades (BRITO e CÂMARA, 1998).

Visando obter elevada produtividade, além da redução de custos com empregados, o produtor rural aumenta o emprego de máquinas agrícolas, da irrigação e de insumos para aumento da produção: fertilizantes, defensivos, corretivos de acidez do solo, engenharia genética, vacinações e energia elétrica, entre outros. Observa-se, entretanto, que cada um desses fatores de produção causa alguma degradação ambiental, resultando na compactação dos solos, na desertificação, na contaminação dos rios, na perda da biodiversidade genética, nas consequências ainda desconhecidas no enfraquecimento de espécies, na expansão descontrolada das fronteiras agrícolas, na destruição de formações vegetais nativas, queimadas na Amazônia e o corte predatório de árvores (MOURA, 2004).

De acordo com Dias (1999), a educação ambiental é um processo por meio do qual as pessoas podem aprender como funciona o ambiente, como dependem dele, como o afetam e como promovem a sua sustentabilidade. Nesta definição, verifica-se a responsabilidade e importância dada a educação ambiental na busca pela transformação social. 


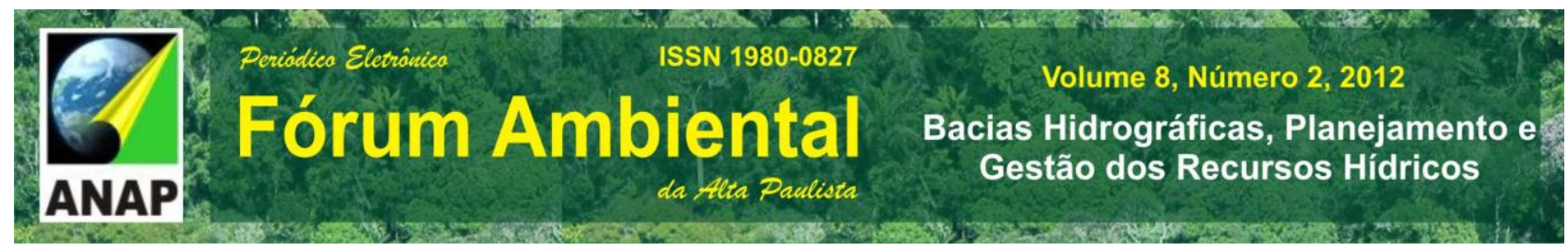

Desde o ano de 2000 está em desenvolvimento na UNESP, Campus de Ilha Solteira, um projeto de diagnóstico sócio-ambiental em propriedades agrícolas (pequenas, médias e grandes) no Estado de São Paulo, de modo a coletar dados sobre as diversas realidades do meio rural do estado. Diversos trabalhos foram realizados no contexto de tal projeto, com a finalidade de avaliar as condições ambientais das propriedades rurais e a percepção ambiental de agricultores, entre os quais podem ser citados o de Arruda et al. (2001), no Assentamento Timboré em Castilho, SP, o de Poleto et al (2004), na Microbacia Hidrográfica do Córrego do Ipê em Ilha Solteira, SP, o de Martins et al. (2005) no Assentamento Cinturão Verde de Ilha Solteira e o de Américo et al. (2007) em Dobrada, SP.

O presente trabalho teve como objetivo investigar a realidade sócio-ambiental de algumas propriedades rurais localizadas no Município de Santa Rita do Passa Quatro, Estado de São Paulo. As informações geradas nesse trabalho podem ser utilizadas como subsídios para o planejamento de programas de educação ambiental na região, bem como para a aplicação de políticas públicas, capazes de contribuir para a resolução de problemas e tomadas de decisões que assegurem a manutenção e conservação do ambiente.

\section{MATERIAL E MÉTODOS}

\subsection{Caracterização da Área de Estudo}

Santa Rita do Passa Quatro, com 27.171 habitantes, é considerada uma estância climática, com clima seco, ventoso e saudável, e topografia levemente ondulada ao norte e oeste e montanhosa a leste e sul, com altitude de 759 metros, atingindo 1.000 metros no Morro Itatiaia (PREFEITURA MUNICIPAL, 2008)

De acordo com a Prefeitura Municipal, o município de Santa Rita do Passa Quatro possui $753 \mathrm{~km}^{2}$ e está localizado a $250 \mathrm{~km}$ da Capital de São Paulo, no encontro aproximado das coordenadas geográficas $21^{\circ} 42^{\prime}$ de Latitude Sul e $47^{\circ} 28^{\prime}$ de Longitude Oeste, com altitude ao redor de759 $\mathrm{m}$. 
O clima da região é Cwa, segundo a classificação de Köeppen (1948), apresentando uma temperatura média anual de $21,1^{\circ} \mathrm{C}$ (média das máximas de $23,5^{\circ} \mathrm{C}$ e das mínimas de $17,5^{\circ} \mathrm{C}$ ), com índice pluviométrico de 1.506,8 mm em média (CEPAGRI, 2008).

A principal atividade econômica do município é a Agropecuária, empreendida por 695 estabelecimentos agropecuários que ocupam uma área de $323 \mathrm{~km}^{2}$.

Outra atividade econômica importante no município é o agroecoturismo, uma vez que a cidade é considerada uma estância climática, inclusive por contemplar áreas de relevante interesse ecológico como o Parque Vassununga, com 150ha, e Cerrado Pé de Gigante, com 1.060ha (PREFEITURA MUNICIPAL, 2008).

A cidade desenvolve turismo o ano todo, sendo rica em belezas naturais, culturais e gastronômicas, oferecendo turismo ecológico pelos morros, cachoeiras e rios e a riqueza histórico-geográfica do turismo rural com sua diversidade gastronômica, fato este que demonstra e reforça a relevância do presente trabalho.

\subsection{Amostragens e Coleta de Dados}

Para realizar a avaliação das condições sócio-econômico-ambientais das propriedades agrícolas no município de Santa Rita do Passa Quatro, formulou-se um questionário com 16 questões contendo quadros com alternativas diversas de respostas. Foram observados os principais fatores que contribuem para a degradação ambiental, assim como as características sócio-econômicas dos entrevistados.

O questionário foi respondido junto aos responsáveis pelas propriedades visitadas, abrangendo um total de 30 propriedades rurais aleatoriamente escolhidas, com área entre 10 e 1.000ha, com uma extensão média de 200ha.

\section{RESULTADOS E DISCUSSÃO}

\subsection{Caracterização sócio-econômica}


A maioria das propriedades visitadas (30\%) apresenta área entre 51 e 100 hectares, evidenciando propriedades de pequeno porte (Tabela 1).

Tabela 1. Porcentagens de área das propriedades rurais visitadas. Santa Rita do Passa Quatro - SP, 2008.

\begin{tabular}{lcc}
\hline Area das Propriedades (ha) & Número de Propriedades & $\mathbf{( \% )}$ \\
\hline Até 10 & 1 & $3,34 \%$ \\
11 a 50 & 4 & $13,33 \%$ \\
51 a 100 & 9 & $30 \%$ \\
101 a 200 & 6 & $20 \%$ \\
201 a 500 & 7 & $23,33 \%$ \\
501 a 1000 & 2 & $6,66 \%$ \\
Maior que 1000 & 1 & $3,34 \%$ \\
\hline Total & $\mathbf{3 0}$ & $\mathbf{1 0 0 \%}$ \\
\hline
\end{tabular}

A produção agropecuária foi citada como fonte de renda em $30 \%$ das propriedades, assim como a aposentadoria ou pensão (30\%) (Figura 1). De acordo com o observado por Martins (2005), em Ilha Solteira (SP), $80 \%$ das propriedades investigadas apontaram como principal fonte de renda a agropecuária, de modo similar ao observado por Américo (2007) na região de Dobrada (SP).

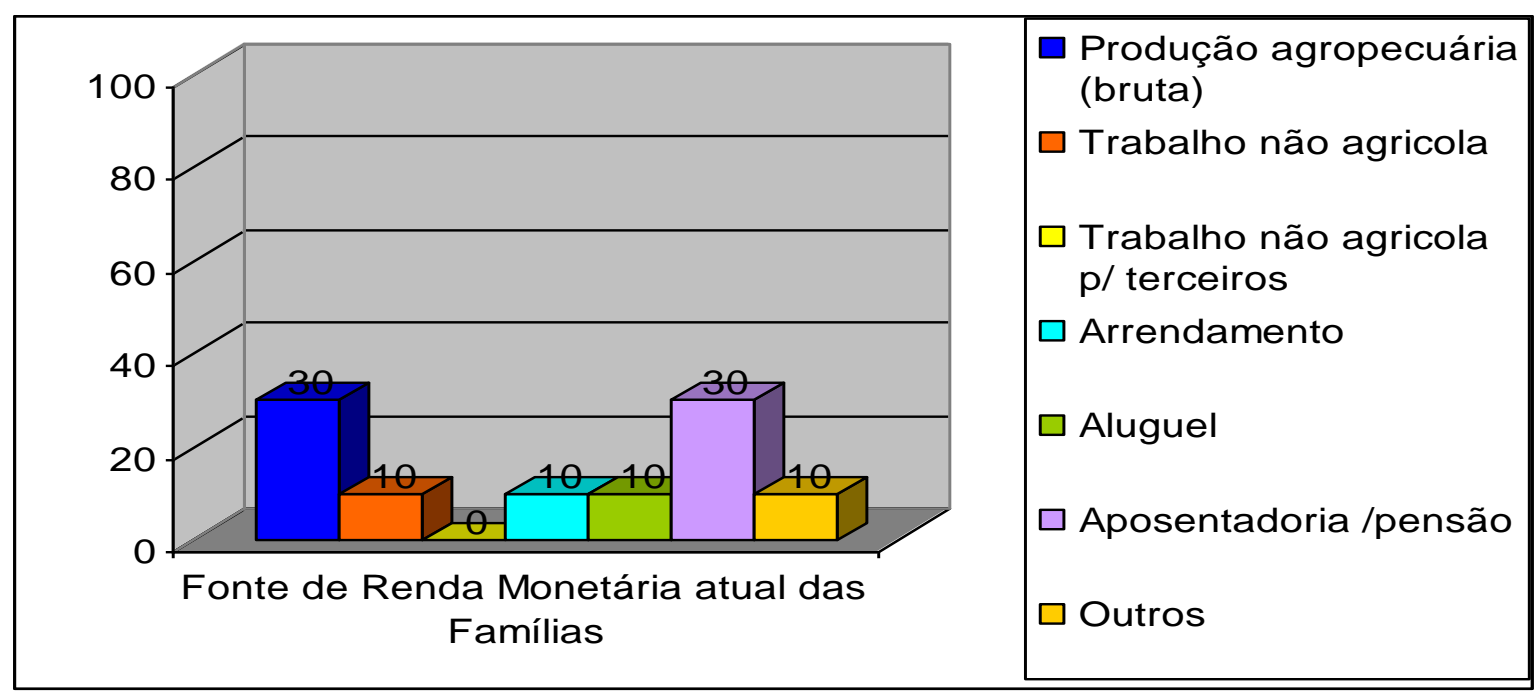

Figura 1. Modalidade de renda familiar das propriedades visitadas. Santa Rita do Passa Quatro - SP, 2008. 
Das trinta propriedades pesquisadas, observa-se que apenas seis relataram dispor de alguma assistência técnica (20\%), fato este que prejudica a atividade agrícola no município.

Com relação à produção vegetal (Figura 2), observa-se que a cultura do milho é predominante, ocorrendo em $25 \%$ das propriedades visitadas.

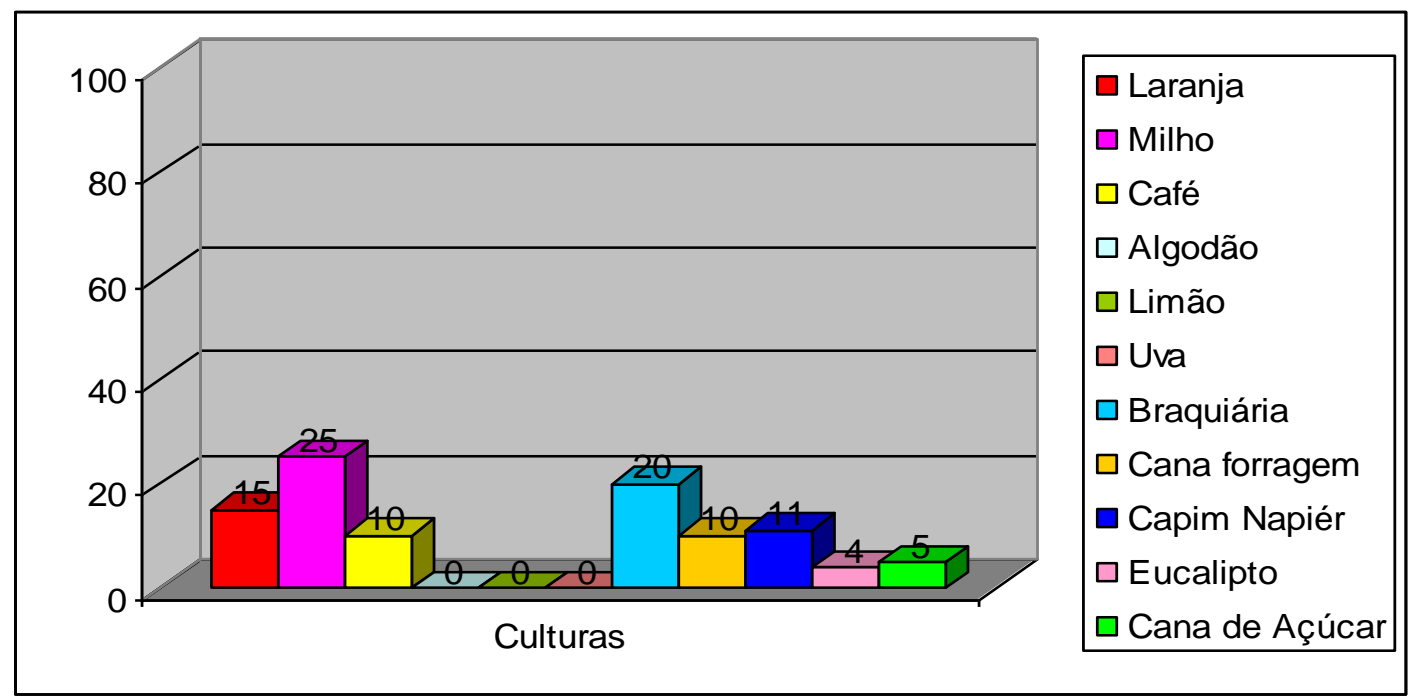

Figura 2. Culturas vegetais nas propriedades visitadas. Santa Rita do Passa Quatro - SP, 2008.

Ainda com relação à produção vegetal, a forte presença da cultura do milho no município parece indicar que esta atividade seja complementar ao cultivo da braquiária, no sentido de destinar-se à alimentação animal, uma vez que a produção animal é expressiva em Santa Rita do Passa Quatro, sendo que a bovinocultura está presente em $61 \%$ das propriedades. (Figura 3). Cabe observar ainda, corroborando este raciocínio, a presença da cultura de cana para forragem e de capim napiér, responsável por 10 e $11 \%$ da produção, respectivamente. 


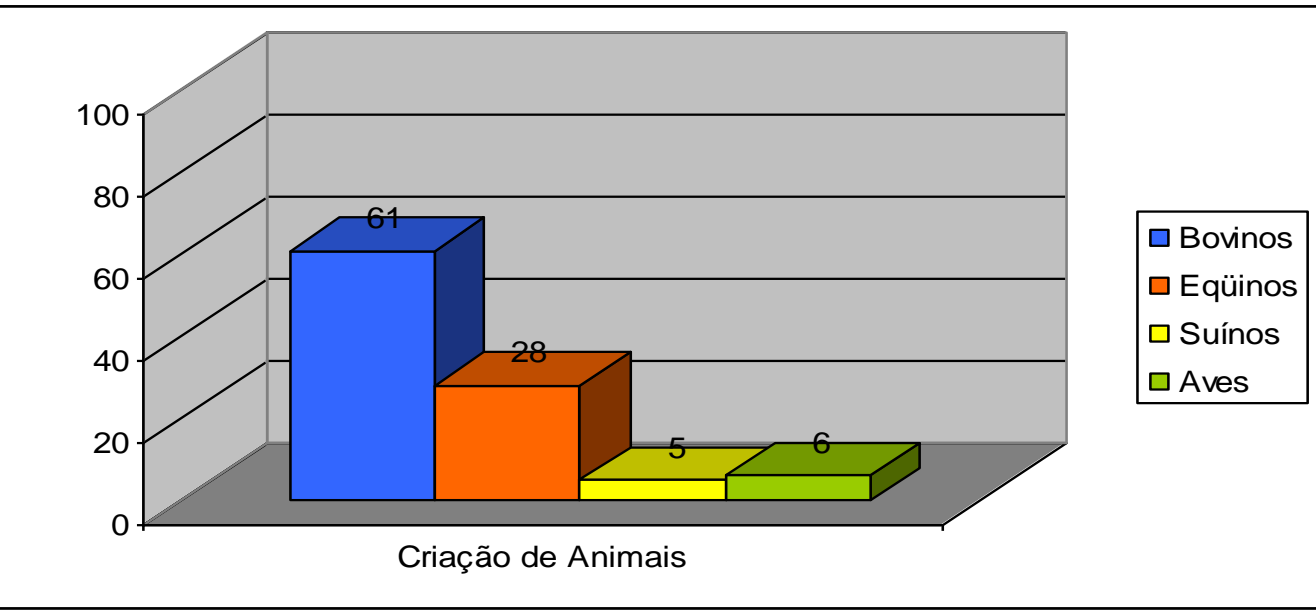

Figura 3. Produção animal nas propriedades visitadas. Santa Rita do Passa Quatro - SP, 2008.

\subsection{Caracterização socioambiental das propriedades.}

As principais fontes de água utilizadas nas propriedades visitadas corresponderam a represas, lagos ou açudes (27\%), córregos (24\%) e poços (24\%) (Figura 4). A utilização de água tratada foi registrada em $70 \%$ das propriedades.

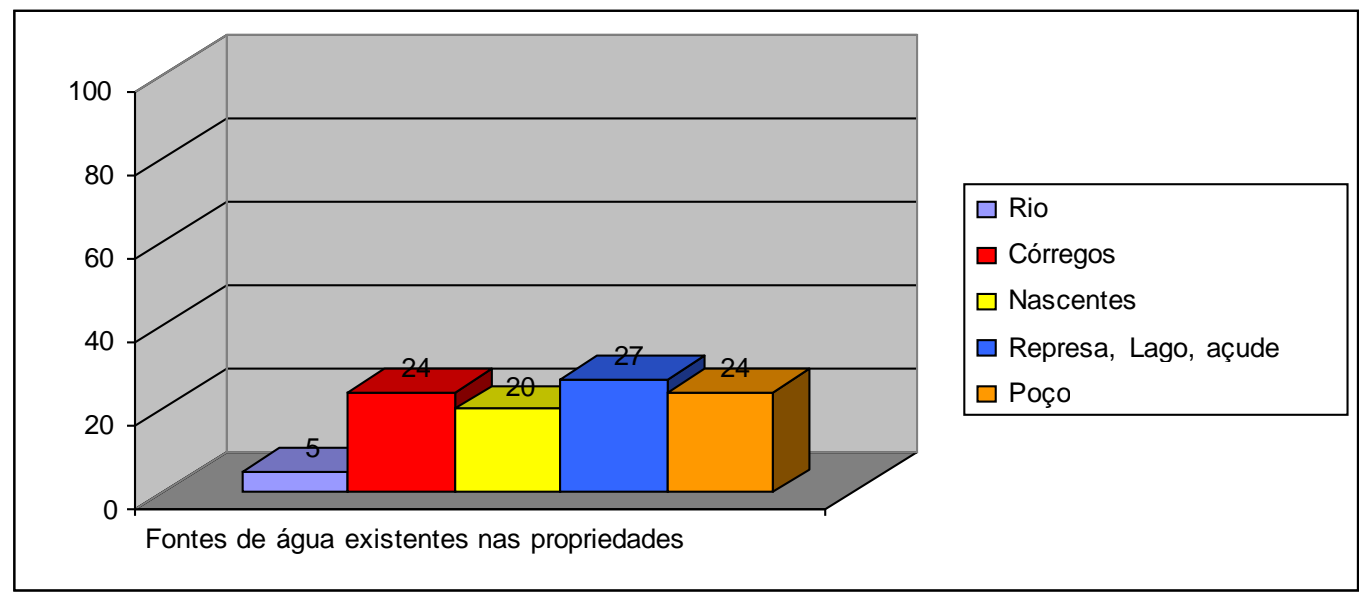

Figura 4. Fontes de água existentes nas propriedades visitadas. Santa Rita do Passa Quatro - SP, 2008.

Com relação à destinação final de esgoto, observa-se que $84 \%$ das propriedades citaram a utilização de fossas. As demais propriedades citaram outras formas de 
destinação final do esgoto, muitas inadequadas como o lançamento direto no solo ou em rios e córregos, o que contribui para a poluição da água e do lençol freático, além de possibilitar a transmissão de doenças e contaminação destas e de outras famílias vizinhas. Este fato deveria ser considerado seriamente pelos órgãos gestores do meio ambiente, responsáveis por tomar as medidas cabíveis para solucionar esse problema.

Todas as propriedades mostraram preocupação em relação à conservação do solo, sendo que $24 \%$ das propriedades visitadas relataram problemas com relação ao manejo e conservação do solo (Figura 5). Entretanto, não foram relatadas situações de assoreamento de cursos d'água.

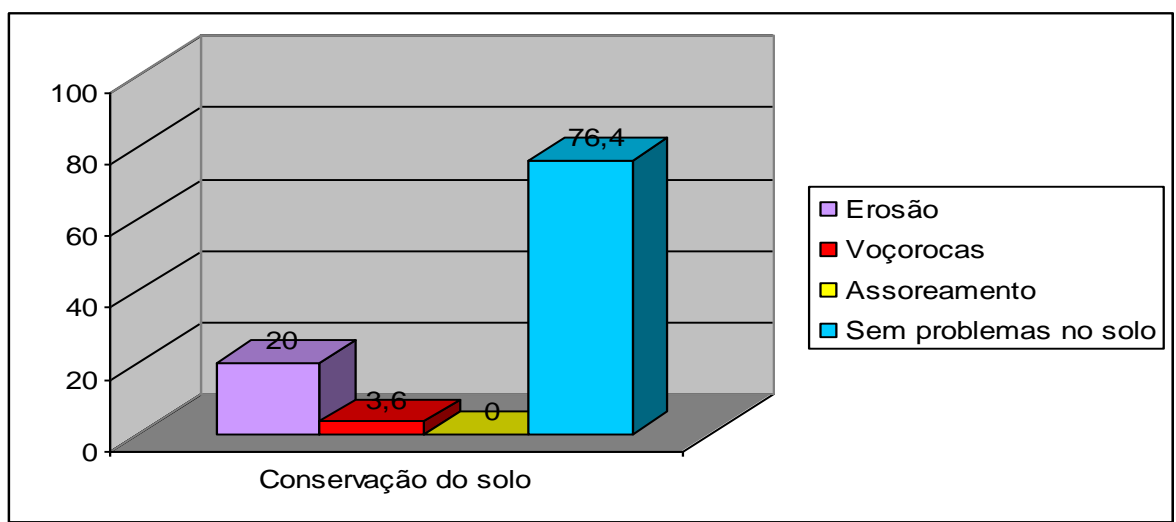

Figura 5. Manejo e conservação do solo das propriedades visitadas. Santa Rita do Passa Quatro - SP, 2008.

$\mathrm{Na}$ região de Dobrada (SP), Américo et.al. (2007) observaram problemas relacionados ao manejo e conservação do solo na maioria das propriedades estudadas, sendo que em $20 \%$ delas foram relatados problemas de erosão do solo e em $63 \%$, assoreamento de cursos d'água.

As matas ciliares foram relatadas como conservadas em $70 \%$ das propriedades. $A$ situação das matas ciliares nas propriedades visitadas no Município de Santa Rita do Passa Quatro difere da situação encontrada em grande parte dos municípios do Estado de São Paulo, onde a maioria dos cursos d'água está desprovida de vegetação ciliar.

Dentre as várias condições que influenciam a conservação do solo, a cobertura vegetal desempenha um papel muito significativo. As matas ciliares, por exemplo, 
apresentam como uma de suas funções, a proteção das margens dos cursos d'água, prevenindo a erosão do solo e, consequentemente, o assoreamento dos cursos d'água. A presença de mata ciliar nas margens dos cursos d'água nas propriedades visitadas e, 0 fato de que não foram relatados problemas de assoreamento dos cursos d'água, possivelmente são situações correlacionadas.

Outro aspecto ambiental analisado foi a forma de eliminação do lixo doméstico e agrícola, que na maioria das vezes contém embalagens de produtos que demoram centenas de anos para decompor, causando diversos danos ao meio (AMÉRICO et al. 2007).

Das propriedades visitadas (Figura 6) 52\% relataram a queima do lixo doméstico. A realização da coleta seletiva por 35\% das propriedades é um aspecto ambiental positivo, muito embora, normalmente, apenas a fração do lixo com melhor valor de mercado seja realmente reciclada.

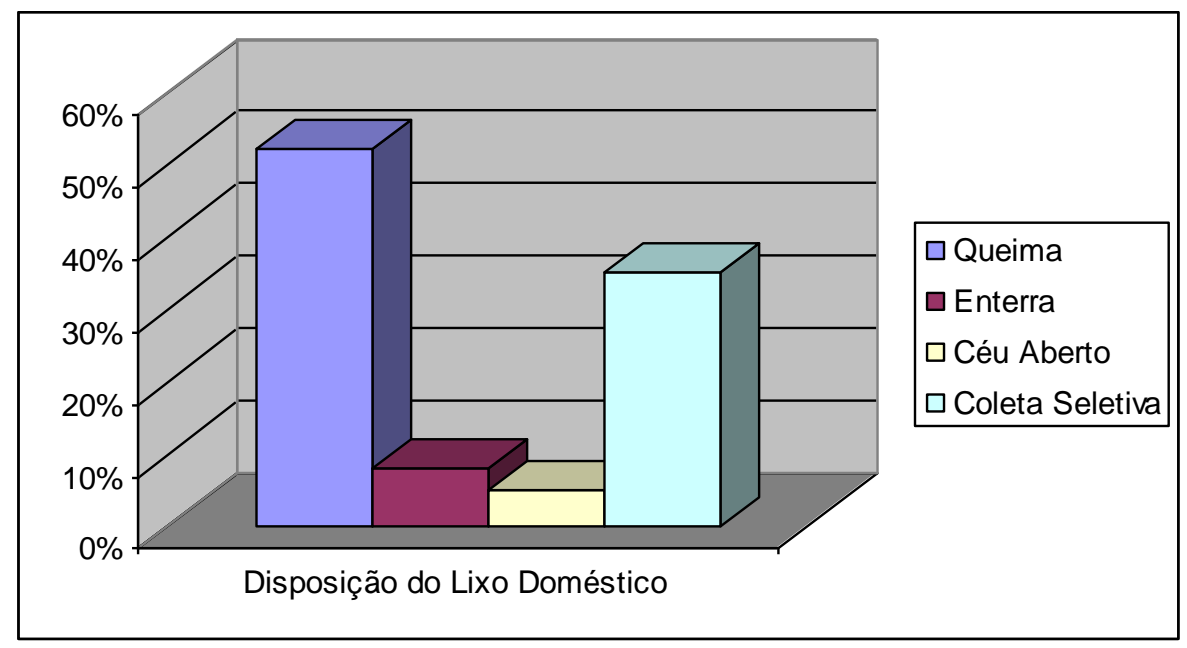

Figura 6. Disposição do lixo doméstico das propriedades visitadas. Santa Rita do Passa Quatro - SP, 2008.

Quanto às embalagens de defensivos agrícolas, 80\% das propriedades enterramnas e apenas 6\% delas entregam esse lixo para coleta especializada. Um dado preocupante é a reutilização dessas embalagens, observada em 14\% das propriedades (Figura 7). 


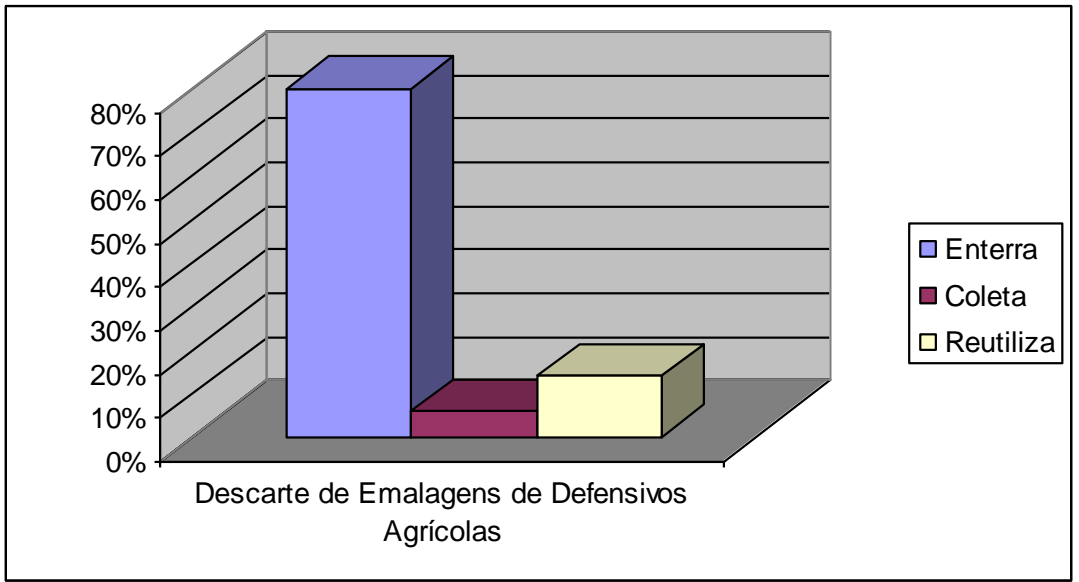

Figura 7. Descarte das embalagens de defensivos agrícolas nas propriedades visitadas. Santa Rita do Passa Quatro - SP, 2008.

Dentre as propriedades que reutilizam as embalagens, 89\% utilizam-nas para formação de mudas; $6 \%$ utilizam-na para mistura de outros produtos e $5 \%$ para colocação de lixo (Figura 8).

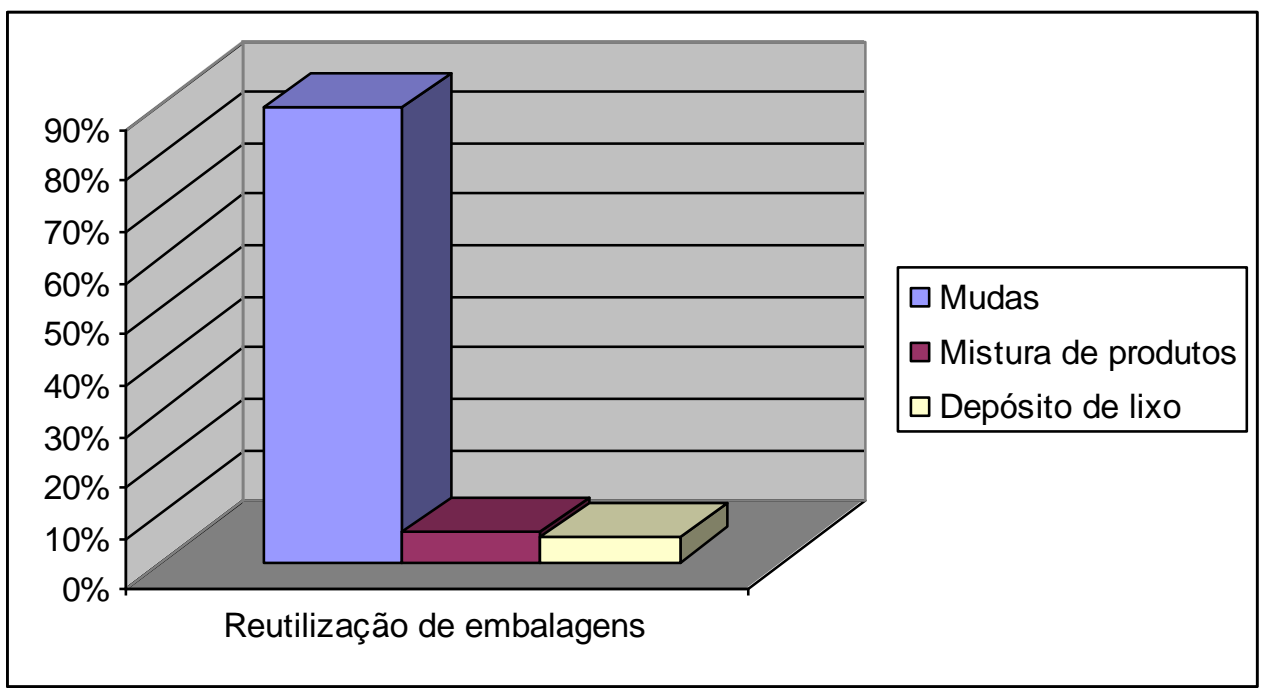

Figura 8. Modo de reutilização das embalagens de defensivos agrícolas nas propriedades visitadas. Santa Rita do Passa Quatro - SP, 2008.

A reutilização de embalagens de defensivos agrícolas, com seus riscos à saúde e ao ambiente, é uma prática ainda muito utilizada no meio rural. No Assentamento Timboré em Castilho (SP), Arruda et al. (2001) relataram que 50\% das embalagens eram 
abandonadas ao ar livre, enquanto que $70 \%$ dos proprietários reaproveitavam as embalagens para uso doméstico.

Das 30 propriedades estudadas, 18 delas (60\%) faziam uso de equipamentos de proteção individual (EPI), mesmo que incompletos. A não utilização de equipamento de proteção individual pode levar à contaminação dos trabalhadores. Foi relatado algum tipo de contaminação em 14\% das propriedades, em que não foram utilizados EPIs para a aplicação de defensivos agrícolas.

\section{CONCLUSÕES}

De acordo com os dados obtidos nas condições do presente trabalho, pode-se concluir que alguns problemas ambientais foram observados, embora a maioria das propriedades apresentem matas ciliares conservadas, poucos problemas relacionados ao manejo e conservação do solo e uma boa percepção no que se refere a importância da conservação dos recursos naturais.

Os maiores problemas foram observados com relação ao descarte do lixo, tanto doméstico quanto agrícola, pois a maioria das propriedades queima ou enterra seus resíduos sólidos. A reutilização das embalagens dos defensivos agrícolas também se torna um fato preocupante, juntamente com a falta de utilização de equipamentos de proteção e falta de assistência técnica.

Contudo, os principais problemas relatados nas propriedades foram a falta de recursos financeiros e a falta de incentivo do Governo.

Como possíveis soluções para os problemas relatados, faz-se necessário um maior comprometimento da comunidade em geral e maior estímulo de prefeitura ao agroecoturismo do município, tornando este uma segunda alternativa de renda para as propriedades rurais, além de programas de educação ambiental voltados para a comunidade em geral. 


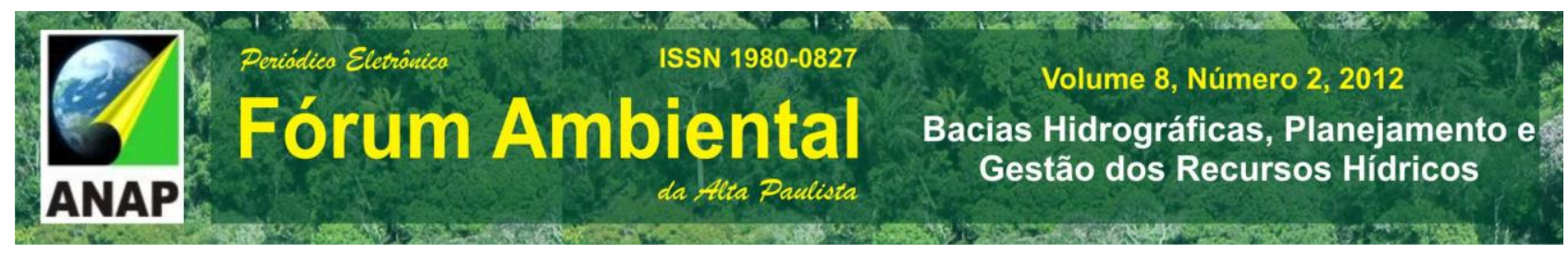

\section{REFERÊNCIAS}

AMÉRICO, J.H.P.; CARVALHO, S.L.; FREITAS LIMA, E.A.C.;ARAÚJO, C.A.M. Avaliação das condições ambientais de algumas propriedades agrícolas e percepção ambiental de produtores rurais da região de Dobrada - SP. In: Anais do VIII Congresso de Ecologia do Brasil. Caxambu - MG, 2007.

AMORIM, D. A. Levantamento de Áreas Degradadas da Bacia do Alto do Rio Jacareí-Guaçu: propostas para recuperação. São Carlos, 1997. 121p. Dissertação de Mestrado - EESC/CRHEA, Universidade de São Paulo.

ARRUDA, S.A. CARVALHO, S.L.; FREITAS LIMA, E.A.C.;ARAÚJO, C.A.M. Percepção ambiental de produtores rurais e das condições ambientais de seus lotes agrícolas no Assentamento Timboré em Castilho-SP. In: III Encontro Sobre Educação Ambiental na Agricultura. Campinas-SP, 2001.

BRITO, F.A. e CÂMARA, B.D. Democratização e Gestão Ambiental: em busca do desenvolvimento sustentável, 2.ed. Petrópolis, RJ, Vozes, 1998,p.36-42.

CEPAGRI. Clima do Município de Santa Rita do Passa Quatro. Disponível em: http $<$ www.cpa.unicamp.br>. Acesso em 01 de julho de 2008.

DIAS, G.F. Elementos para capacitação em educação ambiental. Iheus: Editus, 1999.

IBGE, 2006. Cidades. Disponível em: http <www.ibge.gov.br>. Acesso em 01 de julho de 2008. KÖEPPEN, W. Climatologia. México: Fondo de Cultura Econômica, 1948. 478p.

MARTINS, M. Avaliação das condições sócio-economicas-ambientais de algumas propriedades no município de Ilha Solteira. São Paulo. Monografia apresentada ao Curso de Agronomia da Faculdade de Engenharia-Campus de llha Solteira-São Paulo. 2005.

MOURA, L.A.A. Qualidade e Gestão Ambiental, 4.ed. São Paulo, Juarez de Oliveira, 2004, p.2745.

POLETO, C.; CARVALHO, S.L; FREITAS LIMA, E.C. Problemas de degradação ambiental em uma microbacia hidrográfica situada no município de llha Solteira - SP, Brasil e sua percepção pelos proprietários rurais. Holos Environment, v. 4, n.1, p. 68-80, 2004.

PREFEITURA MUNICIPAL. Santa Rita do Passa Quatro. Disponível em: http $<$ www.santaritadopassaquatro.sp.gov.br> . Acesso em 01 de julho de 2008. 